\title{
Goodbye Starling's Law, Hello G Tube
}

\section{Ahmed N Ghanem*}

Department of Urology, Mansoura University, Egypt

*Corresponding author: Ahmed N Ghanem, Faculty of Medicine, Department of Urology, Mansoura University, Retired Consultant Urologist Surgeon, No1 President Mubarak Street, Mansoura 35511, Egypt, Tel: 00201020883243; Email: anmghanem1@gmail.com

\section{Editorial}

Volume 5 Issue 1

Received Date: April 02, 2020

Published Date: April 15, 2020

DOI: $10.23880 /$ oajun-16000175

\section{Editorial}

Substantial physics and physiological evidence with clinical relevance and significance currently exists that affirms Starling's law is wrong [1]. Starling [2] based his hypothesis on Poiseuille's work on strait uniform diameter tube [3] in which the hydrostatic pressure causes filtration, and the oncotic pressure force of plasma albumin causes reabsorption [4]. Recent evidence demonstrates Starling's law is wrong on both oncotic [5-10] and hydrostatic pressure $[1,11,12]$ forces, and provides the correct replacement of hydrodynamic of the porous orifice G tube [1] (Figure 1).

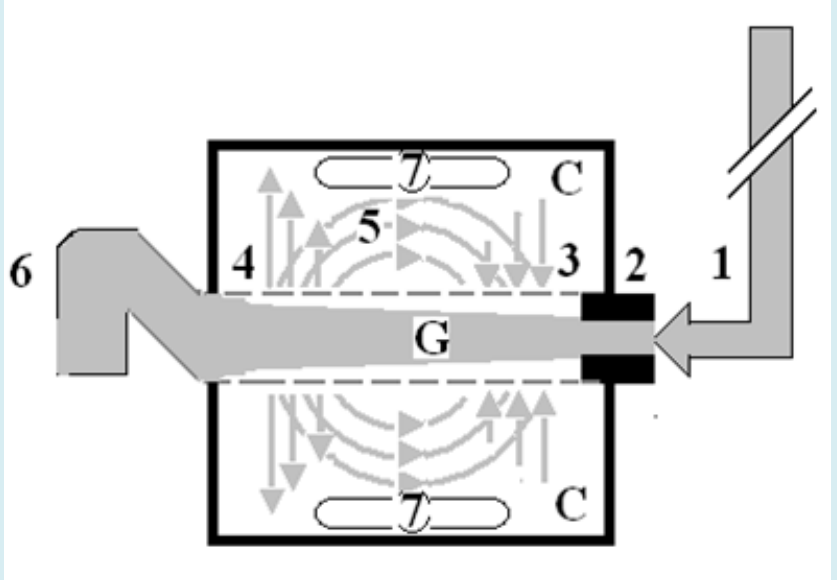

Figure 1 shows a diagrammatic representation of the hydrodynamic of $\mathrm{G}$ tube and surrounding chamber $\mathrm{C}$. The $\mathrm{G}$ tube is a plastic porous tube and the chamber $\mathrm{C}$ around it is another bigger plastic tube to form the G-C apparatus- akin to capillary-interstitial fluid unit. The diagram numbers should read as follows:

1. The inflow pressure pushes fluid through the orifice

2. Creating fluid jet in the lumen of the $G$ tube**.

3. The fluid jet creates negative side pressure gradient causing suction maximal over the proximal part of the $G$ tube near the inlet that sucks fluid into lumen.

4. The side pressure gradient turns positive pushing fluid out of lumen maximum over the distal part near the outlet.

5. Thus, the fluid around G tube inside C moves in magnetic field-like circulation (5) taking an opposite direction to lumen flow of G. tube.

6. The inflow pressure 1 and orifice 2 induce the negative side pressure energy creating the dynamic G-C circulation phenomenon that is rapid, autonomous and efficient in moving fluid out from the $\mathrm{G}$ tube lumen at 4, irrigating $\mathrm{C}$ at 5 , then sucking it back again at 3 , 7. Maintaining net negative energy pressure inside chamber $\mathrm{C}$.

**Note the shape of the fluid jet inside the G tube (Cone shaped), having a diameter of the inlet on right hand side and the diameter of the exit at left hand side (G tube diameter). I lost the photo on which the fluid jet was drawn, using tea leaves of fine and coarse sizes that runs in the center of $G$ tube leaving the outer zone near the wall of $G$ tube clear. Fine leaves exit $G$ tube at pores near its outlet. This may explain the finding in real capillary of the protein-free (and erythrocyte-free) sub-endothelial zone in the Glycocalyx paradigm (Woodcock and Woodcock 2012). 


\section{Open Access Journal of Urology \& Nephrology}

The capillary has a pre-capillary sphincter and wide pores that allow the passage of molecules larger than plasma proteins [13]. This makes the capillary a porous orifice $(G)$ tube with different hydrodynamic from Poiseuille's tube. The side pressure of G tube causes suction not filtration. The wide capillary pores nullify the oncotic force in vivo based on biochemical and clinical research using albumin and hyroxyethyl starch. The osmotic chemical composition of various body fluids is identical to plasma proteins. The interstitial fluid (ISF) space has a negative pressure of -7 $\mathrm{cm}$ water [14], so is lymph [15]. Clinical evidence on plasma albumin versus Saline shows no significant difference. This evidence affirms that the oncotic force does not exist in vivo that partly prove Starling's law wrong. Inadequacy in explaining the capillary-ISF transfer, has previously [16] and recently [17] called for reconsideration of Starling's hypothesis.

New physics and physiological research demonstrate that side pressure does not cause filtration across the wall of $\mathrm{G}$ tube, it causes suction. In $\mathrm{G}$ tube the negative side pressure gradient on its wall causing suction maximum near the inlet and turns positive maximum near the exit causing filtration. This creates a circulation between fluid in the lumen of $\mathrm{G}$ tube and surrounding fluid chamber (C) that runs in the opposite direction creating autonomous, dynamic rapid magnetic field like circulation (Figure 1). Physiological study completed the evidence that Starling's law is wrong as the capillary works as $\mathrm{G}$ tube not Poiseuille's tube. Oedema occurred with both albumin and saline when the fluid is run through the vein but not the artery. Both absorption and filtration are autonomous functions of G tube thus fit to replace Starling's law.

The clinical significance is that Starling's law dictates the faulty rules on fluid therapy causing many errors and misconceptions [18] that mislead physicians into giving too much fluid infusions of albumin and crystalloids for the resuscitation of shock which both cause edema of ISF space and vital organs as well as hypervolaemia with hypotension [19]. This shock is mistaken for septic or hemorrhagic shock and is wrongly treated with further huge volume expansion, occurring with both liberal and conservative approach of fluid therapy [20]. This induces volumetric overload shocks [21-24]. Volumetric overload inducing VOS is of 2 types; VOS 1 causes the transurethral resection of the prostate [TURP] syndrome [25], now being linked to the acute respiratory distress syndrome [ARDS] [26,27] that was reported by Ashbaugh, et al. [28] in 1967. ARDS is caused by VOS 2 with high morbidity and mortality and acute kidney injury (AKI) [29] as parts of the multiple organ dysfunction syndrome (MODS) [30]. Volumetric overload induced by persistence to elevate CVP to high level [31] as based on the faulty Starling's law. Work is now in progress that demonstrates VOS Cause ARDS, Constructing the BRIDGE between physics, physiology, biochemistry and clinical medicine [32,33].

\section{References}

1. Ghanem AN (2020) The Correct Replacement for the Wrong Starling's law is the Hydrodynamic of the Porous Orifice (G) Tube: The Complete Physics and physiological Evidence with Clinical Relevance and Significance. Cardiology: Open Access Cardio Open 5(1): 7-15.

2. Starling EH (1886) Factors involved in the causation of dropsy. Lancet ii pp: 1266-1270.

3. Folkow B, Neil E (1971) Circulation. Oxford University Press: London, pp: 1-125.

4. Keele CA, Neil E, Joels N (1982) Sampson Wright Applied Physiology. $13^{\text {th }}$ (Edn.), Oxford University Press, Oxford.

5. Karnovesky MJ (1967) The ultra-structural basis of capillary permeability studied with peroxidase as a tracer. J Cell Biol 35(1): 213-236.

6. Hendry EB (1962) The osmotic pressure and chemical composition of human body fluids. Clin Chem 8(3): 246265.

7. Cochrane Injuries Group Albumin Reviewers (1998) Human albumin administration in the critically ill patients: systemic review of randomized controlled trials: Why albumin may not work. BMJ 317(7153): 235240 .

8. Finfer S, Bellomo R, McEvoy S, Lo SK, Myburgh J, et al. (2006) Effect of baseline serum albumin concentration on outcome of resuscitation with albumin or saline in patients in intensive care units: analysis of data from the saline versus albumin fluid evaluation (SAFE) study. BMJ 333(7577): 1044.

9. Vincent JL (2006) Resuscitation using albumin in critically ill patients: Research in patients at high risk of complications is now needed. BMJ 333(7577): 10291030 .

10. Futier E, Garot M, Godet T, Biais M, Verzilli D, et al. (2020) Effect of Hydroxyethyl Starch vs Saline for Volume Replacement Therapy on Death or Postoperative Complications Among High-Risk Patients Undergoing Major Abdominal Surgery: The FLASH Randomized Clinical Trial. JAMA 323(3): 225-236.

11. Ghanem AN (2001) Magnetic field-like fluid circulation of a porous orifice tube and relevance to the capillaryinterstitial fluid circulation: Preliminary report. Medical Hypotheses 56(3): 325- 334.

12. Ghanem KA, Ghanem AN (2017) The proof and reasons that Starling's law for the capillary- interstitial fluid 


\section{Open Access Journal of Urology \& Nephrology}

transfer is wrong, advancing the hydrodynamics of a porous orifice $(\mathrm{G})$ tube as the real mechanism. Blood Heart and Circ 1(1): 1-7.

13. Rhodin JA (1967) The ultra-structure of mammalian arterioles and pre-capillary sphincters. J Ultrastructure Research 18(1): 181-223.

14. Guyton AC, Coleman TG (1968) Regulation of interstitial fluid volume and pressure. Ann N Y Acad Sci 150(3): 537-547.

15. Calnan JS, Pflug JJ, Chisholm GD, Taylor LM (1972) Pathophysiology of tissue fluid. Proc R Soc Med 65(8): 715-719.

16. Renkin EM (1986) Some consequences of capillary permeability to macromolecules: Starling's hypothesis reconsidered. Am J Physiol 250(5 Pt 2): 706-710.

17. Ghanem KA, Ghanem AN (2017) The Physiological Proof that Starling's Law for the Capillary-Interstitial Fluid Transfer is wrong: Advancing the Porous Orifice (G) Tube Phenomenon as Replacement. Open Acc Res Anatomy 1(2): 1-7.

18. Ghanem AN (2018) The Adult Respiratory Distress Syndrome: Volumetric Overload Shocks in PathoEtiology Correcting Errors and Misconceptions on Fluid Therapy, Vascular and Capillary Physiology. Surg Med Open Acc J 2(2).

19. Ghanem AN (2020) What are Misleading Physicians into giving too much Fluid During Resuscitation of Shock and Surgery that Induces ARDS and/or AKI. Asploro Journal of Biomedical and Clinical Case Reports (in the Press).

20. Woodcock TE, Woodcock TM (2012) Revised Starling equation and the glycocalyx model of trans-vascular fluid exchange: an improved paradigm for prescribing intravenous fluid therapy. Br J Anaesth 108(3): 384-394.

21. Ghanem AN, Ghanem SA (2016) Volumetric Overload Shocks: Why Is Starling's Law for Capillary Interstitial Fluid Transfer Wrong? The Hydrodynamics of a Porous Orifice Tube as Alternative. Surgical Science 7: 245-249.

22. Pindoria N, Ghanem SA, Ghanem KA, Ghanem AN (2017) Volumetric overload shocks in the patho-etiology of the transurethral resection prostatectomy syndrome and acute dilution hyponatraemia. Integr Mol Med 4.

23. Ghanem KA, Ghanem AN (2017) Volumetric overload shocks in the patho-etiology of the transurethral resection prostatectomy syndrome and acute dilution hyponatraemia: The clinical evidence based on 23 case series. Basic Research Journal of Medicine and Clinical Sciences 6(4).

24. Ghanem SA, Ghanem KA, Ghanem AN (2017) Volumetric Overload Shocks in the Patho-Etiology of the Transurethral Resection of the Prostate (TURP) Syndrome and Acute Dilution Hyponatraemia: The Clinical Evidence Based on Prospective Clinical Study of 100 Consecutive TURP Patients. Surg Med Open Access J 1(1): 1-7.

25. Ghanem AN, Ward JP (1990) Osmotic and metabolic sequelae of volumetric overload in relation to the TURP syndrome. Br J Urol 66(1): 71-78.

26. Essayed YS, Ghanem KA, Ghanem SA, Pindoria N, Ghanem AN (2019) Volumetric Overload Shocks (VOS) Resolving the Puzzle of the Transurethral Resection of the Prostate (TURP) Syndrome, Dilution Hyponatraemia (HN) and the Acute Respiratory Distress Syndrome (ARDS): The Minority Report!. EC Cardiology 6(2): 109-122.

27. Ghanem AN (2019) Complication of Fluid Therapy Causing the Acute Respiratory Distress Syndrome: Facts and Comments. The Role of Volumetric Overload Shocks in Patho-aetiology. Archives of Urology 2(1): 21-31.

28. Ashbaugh DG, Bigelow DB, Petty TL, Levine BE (1967) Acute respiratory distress in adults. Lancet 2(7511): 319-323.

29. Schrier RW (2010) Fluid administration in critically ill patients with acute kidney injury. Clin J Am Soc Nephrol 5(4): 733-739.

30. Jones DG, Nantais J, Rezende-Neto JB, Yazdani S, Vegas P, et al. (2018) Crystalloid resuscitation in trauma patients: deleterious effect of $5 \mathrm{~L}$ or more in the first $24 \mathrm{~h}$. BMC Surg 18(1): 93.

31. Ghanem AN (2019) Does Raising the Central Venous Pressure (CVP) in Treating Shock with Fluids Induce Volumetric Overload Shocks (VOS)?. Adv Card Res 1(5).

32. Ghanem AN (2018) Volumetric Overload Shocks: Book. Resolving the puzzles of the transurethral resection of the prostate (TURP) syndrome, acute dilution hyponatraemia (HN) and the acute respiratory distress syndrome (ARDS). Scholars Press USA.

33. Volumetric overload shocks (VOS) cause ARDS: The plenary evidence on patho-aetiology and therapy. Constructing the BRIDGE between physics, physiology, biochemistry and clinical medicine. March 2020 (in progress).

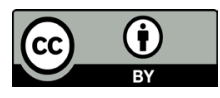

